\title{
A Methodological Approach to Upscale Toward an Agroecology System in EU-LAFSs: The Case of the Parma Bio-District
}

\author{
Marianna Guareschi ${ }^{1, *}$, Michele Maccari ${ }^{2}$, Juan Pablo Sciurano ${ }^{1}$, Filippo Arfini ${ }^{1, *}$ and \\ Andrea Pronti ${ }^{2}$ \\ 1 Department of Management and Economic Science, University of Parma, 43121 Parma, Italy; \\ juanpablo.sciurano@unipr.it \\ 2 Department of Economics and Management, University of Ferrara, Via Voltapaletto 11, 44121 Ferrara, Italy; \\ michele.maccari@unipr.it (M.M.); andrea.pronti@unife.it (A.P.) \\ * Correspondence: mariguare@gmail.com (M.G.); filippo.arfini@unipr.it (F.A.)
}

Received: 29 April 2020; Accepted: 1 July 2020; Published: 3 July 2020

check for updates

\begin{abstract}
The increasing interest in bio-districts is part of the debate on the capacity to integrate agri-food systems and territory in order to improve the quality of life in rural communities. Considering the goals of developing and promoting an innovative territorial rural development approach, the bio-district can become a process toward a more sustainable model represented by the agroecological agriculture system. The paper presents a case study of the Parma bio-district through the approach of a Localized Agri Food System (LAFS) to verify whether bio-districts can be a tool for scaling up towards agroecology. Stakeholder classification and analysis are conducted using an influence-interest matrix. We identified four groups of stakeholders in relation to their interests and power to influence the process. In the case of the Parma bio-district the role of local institutions in dialogue with consumers and producers' associations is crucial for success. We conclude that bio-districts can be a tool for a scaling-up towards agroecology since they can facilitate a synergetic relation between organic and agroecological agriculture, spreading organic agriculture more widely around the local area. However, the involvement of a wide variety of different stakeholders means that governance is a key element in facilitating "cross fertilization" and preventing the process from becoming purely formulaic.
\end{abstract}

Keywords: agroecology; organic agriculture; sustainability; rural development; Local Agri Food System

\section{Introduction}

The concept of sustainability applied to agriculture and rural development was officially introduced by Food and Agriculture Organization (FAO) [1] with the aim to highlight the determinants of sustainability. These determinants are represented as processes that: (i) ensure that the basic nutritional requirements of present and future generations, qualitatively and quantitatively, are met; (ii) provide durable employment, sufficient income and decent living and working conditions for all those engaged in agricultural production; (iii) maintain and, where possible, enhance the productive capacity of the natural resource base to maintain the regenerative capacity of renewable resources, without disrupting the functioning of basic ecological cycles and natural balances, destroying the socio-cultural attributes of rural communities, or contaminating the environment; and (iv) reduce the vulnerability of the agriculture sector to adverse natural and socio-economic factors and other risks, and to strengthen self-reliance.

Three particularly interesting aspects of this vision are as follows: (i) sustainability is not a condition but a process; (ii) it develops "from farm to fork" strategy; (iii) it focuses on the preservation 
of the "socio-cultural attributes of rural communities" and the environment. To be sustainable, therefore, it is necessary to act on production and consumption in environmental, social and economic dimensions through a management process that takes into consideration the relationships between people, in other words, the social inclusion of actors.

These concepts are found in different settings and formalizations in different parts of the world. In developing countries, where large intensive farms co-exist with extensive smallholdings and where environmental policies and subsistence strategies are pursued, sustainable agriculture is represented by agroecological farming systems. In developed countries, on the other hand, where agricultural production is mainly carried out by commercial farms and is separate from the consumption of food, sustainable agriculture is required to comply with agricultural policy and is necessarily formalized. In Europe in particular, the production system closest to the principles of sustainability expressed by FAO is organic agriculture as regulated by the European Union Regulation [2]. Agroecology and Organic Agriculture therefore have different characteristics and pursue different objectives which can be summarized as follows.

\subsection{Agroecology}

Agroecology is based on applying ecological concepts and principles to optimize interactions between plants, animals, humans and the environment while taking into consideration the social aspects of a sustainable and fair food system. Agroecology has several goals, including building synergies, supporting food production and food security and nutrition, while retaining the ecosystem services and biodiversity that are essential for sustainable agriculture.

The principles of agroecology were first set out in the 1930s in a description of ecological principles of agriculture [3]. In the following years the concept emerged as a form of resistance to the ongoing "green revolution" which was based on production simplification through monocultures and the industrialization of all aspects of food production, processing and distribution, with the increasing corporate control and dominance of the food system [4]. The concept of agroecology has evolved through the years and inspired an increasing number of people and institutions worldwide, but is perceived differently by different actors [5,6]. Researchers currently agree that the term agroecology has three aspects. It started as a scientific discipline, has evolved into a set of agricultural practices, and finally, is also a movement that incorporates social justice, food sovereignty and the preservation of cultural identities $[7,8]$. Agroecological agriculture is aimed at designing agro-ecosystems with minimal dependence on external inputs, promoting agricultural diversification to favor biological interactions and benefit from synergies between the components of the agro-ecosystem in terms of soil fertility and the support of productivity [9].

Nowadays, agroecology is no longer applicable only to developing countries. In the EU the Association of Agroecology Europe supports agroecology by promoting training courses and the political/scientific debate among European stakeholders [10], while in the USA, agroecology is considered a tool to support agricultural smallholders in their business [11,12].

\subsection{Organic Agriculture}

In Europe, organic agriculture is one of the Food Quality schemes which characterize the European agricultural model. It was introduced in 1991 with Regulation (EEC) number 2092/91 [13] which was subsequently reformed in 2007 with Regulation (EC) number 834/2007 [14] and again in 2018 with Regulation (EU) 2018/848 [2]. This redefines the principles of organic production in Europe and introduces rules for the management and labelling of organic products of both plant and animal origin (including aquaculture). The latest Regulation will enter into force in 2021 and will entail significant changes in production structure and the market. It is important to remember that organic agriculture has so far grown mainly thanks to leveraging of public funding provided through the rural development programmes defined at the regional level for each EU country. It is also important to note that the European Organic Agriculture system concerns exclusively the production phase. It sets 
production rules that comply with the EU Regulation, and interfaces with consumers only through a homogeneous labelling system for all European countries. To guarantee to consumers that products are actually organic, the producers are subjected to third party verification by an independent certification body paid for by the producers themselves. In this respect, organic products are "trust goods" for consumers, and the effectiveness of this Food Quality scheme depends solely on the level of knowledge and, particularly, on the trust that consumers have in EU logos and the certification system.

European organic agriculture is also inspired by, and indirectly promotes, sustainability, and particularly sustainable rural development. The Scheme does not however directly involve society or consumers, and although it incorporates many agroecological principles, it should not be considered to be synonymous with agroecology [8,15-18]. A common feature of the two systems is the certification system certifying compliance with rules for the use of consumers. However, the difference is that the European organic system uses third-party certification, while agroecology uses "second-party certification" carried out by a panel made up of other local producers and, sometimes, consumers. This procedure is a Participatory Guarantee System (PGS) and is built on a foundation of trust, social networks, and knowledge exchange [19]. It is based on procedures that are not generally considered suitable for highly structured and formalized supply chains like European ones.

The European Organic Food Quality scheme has had undeniable success, but problems on both the consumption and production sides should be noted. On the consumer side, many consumers do not know enough about the certification rules and the meaning of the logo [20] and, as a consequence, they have little faith in Organic certification. On the production side, in addition to the fact that some inputs deemed unsuitable for organic agriculture are permitted (such as copper), some producers do not participate as they consider themselves to be discriminated against [21]. This selection effect is particularly strong for small producers who despite EU rural development programme subsidies often opt not to participate in the scheme. They often seek alternative commercial channels to sell to consumers directly, for example through farmers' markets or Solidarity Purchasing Groups.

\subsection{Reasons for Bio-Districts}

In an attempt to increase the commercial strength of producers and raise levels of consumer confidence in organic products, one response in Italy and Europe is the growth of "bio-districts". These are homogeneous areas with strong organic production. The conceptual framework of the bio-district derives from Becattini's concept of the industrial district [22], defined as a local territorial area characterized by a high concentration of small businesses with a high level of specialization and having a potential for local development. This concept is also similar to a "rural district" where the specialization is related to the agriculture and rural services [23]. Bio-districts can be therefore identified as local production systems in which organic methods are prevalent but-at the same time- they are closely connected to other economic, environmental and socio-cultural elements. In districts with strong agricultural output, agriculture integrates with aspects such as artisan production, tourism and recreation; the safeguarding of soil, water and air; the protection of the landscape and the conservation of biodiversity and the socio-cultural characteristics of local communities.

Bio-districts contribute to the integration of economic activities and social functions into a single system, in which "farmers, citizens, tour operators, associations and public administrations enter into an agreement for the sustainable management of local resources, starting from the organic production and consumption model" [24]. As in industrial and rural districts, coordination takes place through cooperation between different stakeholders. The core of the agreement between stakeholders aims at the sustainable management of local resources [25].

In Italy, 34 operating bio-districts were recorded in 2019 [26]. The first bio-district was set up in 2009 in the Cilento area of Campania in Southern Italy and was promoted by the Italian Association for Organic Agriculture (AIAB) with the aim of developing agricultural chains embedded into the area. In the first step, organic agriculture was considered a tool for implementing local development strategies which connected local products with natural and cultural values. Between 2013 and 2014, 
five more bio-districts were set up with support from AIAB with a precise identification strategy based on the existence of high levels of organic productions in the areas. In the following phase, the increased adoption of organic practices by Italian farmers changed the view of organic agriculture from a starting point for bio-districts to being an objective of local development strategies [26]. Since this change in the paradigm of bio-districts, private and public actors such as consumer associations, public administrations and farmers' organizations have been actively involved in bio-district governance and operational activities. In order to regulate and support these local processes, some Italian regional governments introduced bio-district regulations (Liguria L.R. 66/2009; Sardinia L.R. 16/2014; Lazio L.R. 11/2019; Tuscany L.R. 51/2019) while in other Italian regions there are no particular legislative constraints. In 2017 bio-districts were recognized in Italian legislation as areas where organic farmers, processors and consumer associations or public administrations make formal agreements to promote organic agriculture and sustainable management of local resources [27].

Although several bio-districts are now in existence, there are no "successful" organizational models, and several critical issues remain. The main problems concern weak governance, weaknesses in communication and low levels of financial resources [28] in the organizations which manage the bio-district activities.

\subsection{Scaling up Agroecology}

The increasing interest in bio-districts is part of the debate on the capacity to integrate agri-food systems and the local area in order to improve quality of life in rural communities. The debate covers a number of economic, environmental and social challenges that can be summarized as follows: (i) how to make agriculture more profitable by creating new market opportunities for producers by stimulating local markets, public procurement and tourism; (ii) how to make agriculture more sustainable by reducing the environmental impact of farming on natural resources and preserving biodiversity; (iii) how to enhance social capital—with a specific focus on youth—and enhance the quality of the purchase and consumption of food at the local level.

In these aspects, in the European context, the introduction of a social element gives bio-districts the typical characteristics of the rural district, while reinforcing the process of sustainable development. The bio-district can go further than a simple bio-region towards the goals of developing and promoting an innovative territorial rural development approach, and contributing to the socio-economic regeneration of specific areas and territories. It can become a process towards a more sustainable model represented by the agroecology agricultural system. The expectation of bio-district promoters in Italy is to approach agroecological production and consumption models, and in this way overcome certain limits of organic agriculture (such as cost of certifications or accessibility for lower income people). It is, however, legitimate to ask whether agroecology can exist alongside a strongly conventional and formalized agricultural model. There may be a risk of an "inverted cross-fertilization" that reduces the regenerative potential and the level of sustainability of agroecology. It is also important to identify the positions of the main stakeholders who may see agroecology as an innovative process capable of combining demand and consumption at the local level and with a sustainable perspective.

Given the growing attention to agroecology and the spread of the bio-district production model, this two-part study investigates whether bio-districts can be a tool for scaling-up towards agroecological agriculture. The first part describes a bio-district model that brings together production and sustainable consumption on a local scale; the second part defines the positions of stakeholders regarding its realization.

The work is organized in three sections. Section 2 describes the bio-district of Parma, how it was created by local stakeholders and how it can be represented within the theoretical framework of LAFS. Stakeholder perception is analyzed through an influence-interest matrix. In Section 3 the main results of the stakeholder classification and analysis are presented. Finally, Section 4 discusses the view that the Parma bio-district can be a tool to scale up towards agroecology. 


\section{Materials and Methods}

\subsection{Parma Bio-District Case Study}

This paper considers as a case study area the Province of Parma (Figure 1), one of the provinces of Emilia-Romagna region, Italy, where the Parma bio-district is at an advanced planning stage. The Parma area has a long tradition of quality food. It is widely considered the capital of the "Italian Food Valley" and is officially a UNESCO Creative City of Gastronomy. Big food companies, small producers and food markets, rural festivals, and Solidarity Purchasing Groups all co-exist in the area. On one hand, there is an intensive export-oriented agricultural model, and on the other, small farms oriented to preserving biodiversity and maintaining a direct relationship with consumers. The local agri-food sector features important social and productive aspects: (i) The area is famous for products bearing geographical indications (both PDO and PGI) known all over the world for quality and reputation and represented by governance bodies like the Consortium of Parmigiano Reggiano, Consortium of Parma Ham, Consortium of Culatello Zibello, Consortium of Salame Felino, and the Consortium of Borgotaro Mushroom; (ii) Tomato growers represented by three producer organizations (tomato firms together with the Parma local administration make up a branch organization called "Tomato District of Parma"); (iii) Wine-gastronomic routes that develop local marketing strategies promoting tourism that enhances food production; (iv) Big processing companies producing preserves, sugar and pasta having headquarters in the Province of Parma; (v) Other intermediate institutions acting on behalf of members and supporting the functioning of their respective industries including agricultural Unions, the Experimental Station for the Food Preserving Industry (SSICA), the European Food Safety Agency (EFSA), certification bodies; local intermediate institutions (Chamber of Commerce, the LEADER agency, the Parma Trade Fair Corporation), other public administration institutions (including the "Mountain Communities" and regional parks). All these institutions share common goals, produce common goods and are interconnected working in the same area, the Province of Parma [29].

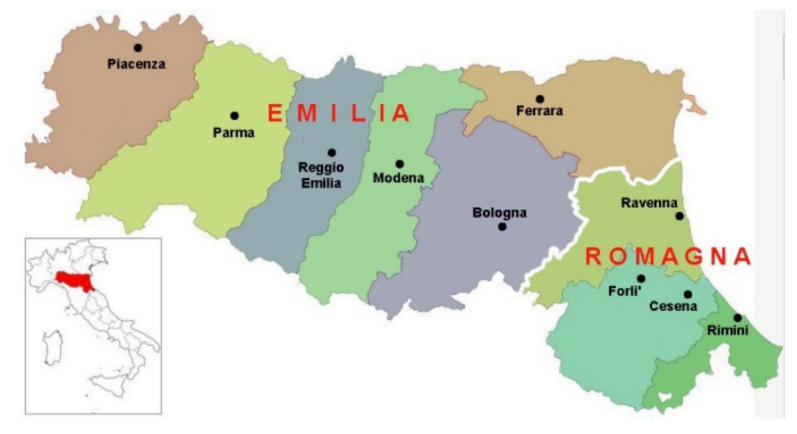

(a)

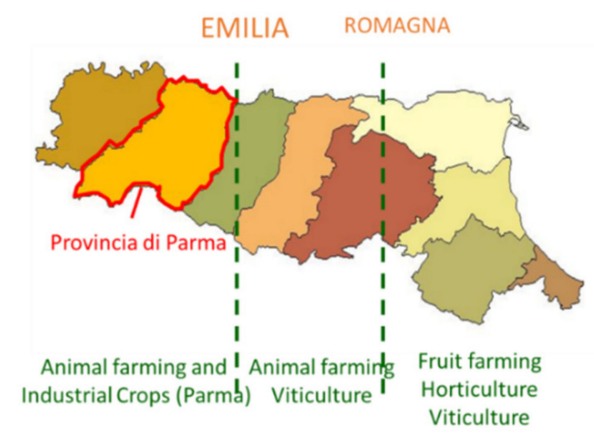

(b)

Figure 1. (a) Emilia Romagna region and Province of Parma; (b) Emilia Romagna region and main agricultural sectors.

It is important to note that from the agricultural point of view, the Province of Parma is the largest area under EU organic production in Emilia Romagna. In 2018, there were 859 organic producers and processors and the Used Agricultural Area (UAA) of organic farming was 24,900 ha, representing almost $20 \%$ of the total UAA area of Parma Province. Forty-one percent of total organic farmers and processors are small famers (up to 15 ha) representing 11\% of total organic UAA of Parma Province (authors' own elaboration based on data for the Emilia Romagna region for the year 2018).

Various alternative food networks also exist in the area. The first Solidarity Purchasing Group (SPG) was set up in the Province of Parma, in Fidenza, in 1994. Currently, the Parma Province has 23 SPGs, organized in a network supported by the District of Solidarity Economy of Parma (DES). There are also numerous local farmers' markets such as La Corte and Campagna Amica, mainly formed by 
Zero Food Kilometer and/or organic farmers, and Mercatiamo managed by organic producers taking part in a Participatory Guarantee System (PGS), a scheme based on ethical principles and trust between consumer and producers.

The idea of establishing the Parma bio-district appeared in May 2018 with the aim to match supply, especially from small producers, and demand, represented by alternative food networks. It originated among members of Sustainable Parma, an association of citizens who created the project Mercatiamo, supported by the District of Solidarity Economy of Parma in 2017. Mercatiamo is a network of producers and consumers aiming at promoting and enhancing the typical products of the territory and at helping to build a sustainable local economy. The network organizes two weekly markets which involve 23 local farmers, producing organic food and/or belonging to the Participatory Guarantee Systems (PGS). Mercatiamo is based on solidarity values and trust among producers and between producers and consumers, with the idea of building community through food. Mercatiamo complies with the Regional Law on the Solidarity Economy No.19 of 23/072014 and is based on the ten pillars of the solidarity economy: collective management of common goods, respect of natural resources, collaboration and cooperation, relationship construction, links with the local area, preserving small initiatives, networking, social transformation, respect of human rights and retrenchment of role of the market. (cf. RES, 2011). The network follows the principles of the circular economy, pursuing a strategy of zero waste and promoting its principles among all members. Members are encouraged to reduce packaging, sell bulk products and use recyclable, reusable and compostable packaging. Finally, it promotes nutrition education, respect for the environment and social responsibility through outreach activities in schools and demonstrations, and so on.

A set of local stakeholders were initially involved by Mercatiamo in a steering group pursuing the aim of creating a bio-district covering the Province of Parma. Stakeholders included the University of Parma, research centers specialized in organic production, an association of small organic farms, other consumer associations and the local administration of Parma. The steering group has a strong female component: the representatives of associations such as Sustainable Parma or the DES are women. At the same time, the small farmers included in Mercatiamo are mostly new-rurals with a strong commitment to social responsibility and environment.

From the start, the objectives were to spread the principle of organic and agroecological agriculture and solidarity economic value across the whole area, and to include different actors, such as large-medium farmers, research and public institutions. The initial goals were also to create a network suitable to help organic producers to solve agronomic problems, supporting the transition toward agroecological agriculture and to increase the marketing capacity by the identification and the setting up of specific organic marketing channels. Thus, organic farming is the basic requirement to take part in the Parma bio-district. However, the Parma bio-district would support the agroecological transition introducing, in addition, regulations based on agroecological practices to increase the standard of sustainability in the Parma area.

Initial steering group activities were: 1 . Drafting a bio-district vision, objectives and rules; 2. Collecting stakeholders' views on the vision, objectives and rules; 3 . Drafting the institutional design of the bio-district. The University of Parma was given the role of coordinator and facilitator of the process. The University aims to promote research on organic agriculture and on creating new forms of marketing and organization which should enable economic spillover in the Province. The University interviewed and involved in the project a large number of stakeholders from different categories: production (farmers and processing firms), distribution (the Agri-food and Logistics Center of Parma, retailers, Solidarity Purchasing Groups, local markets, restaurants), services/research and technology transfer (certain departments of the University of Parma, the organic experimental farm Podere Stuard, the Experimental Station for the Food Preserving Industry (SSICA)), and institutions and local associations including both producer and consumer associations. Finally, the Administration of Province of Parma also supports the promotion of the bio-district of Parma, publicizing the project in other municipalities and local institutions, with the collaboration of the project founding group. 
Setting the rules governing the Parma bio-district was complex, as they were defined through an iterative process between the University and the initial stakeholders. The following rules were agreed on: (i) The bio-district will comprise the overall area of the Province of Parma; (ii) Farmers, processors, traders, retailers of organic products that are produced and processed in the Province of Parma can be part of the bio-district. Consumer associations, local institutions, research and training centers are accepted as members; (iii) Every producer respecting the rules can be part of the Parma bio-district; (iv) The bio-district will be organized as a nonprofit organization and will be managed by representatives of different stakeholders; (v) Products of the bio-district will be labelled by a specific trademark managed by the governance body. There are three different labels: one for organic products from the Parma area regulated according to the European regulations; one for organic products from the Parma area, which include additional agroecological practices; and one for organic products from the Parma area which include additional agroecological practices produced by smallholders farms and following the Participatory Guarantee Systems (PGS). Moreover, the Parma bio-district will: (i) promote products and communicate with consumers; (ii) supply technological, managerial services and training activities; (iii) support market access; (iv) support the sharing of knowledge and experience between members.

\subsection{The LAFS Approach and Stakeholder Analysis}

The concept of "industrial district" or "rural district" is in some ways insufficient to describe the feature and the governance logic of the Parma bio-district. The Localized Agri-Food System (LAFS) approach, on the other hand, is widely used to study the common socio-economic basis of rural regions specialized in agri-food production, and because of the importance of social, economic and environmental links it is more useful in this case.

LAFSs are a type of organization between territorial actors which enhance the natural, social, economic and cultural resources of a territory, promoting sustainable development. Specifically, LAFS generates a link between agri-food production and its territory, where public actors and civil society promote synergies of collective action to define development strategies specific to their territorial identity [30].

In fact, the first conceptualizations of LAFS in the mid-1990s identified three main elements: place, social relations and institutions. The "place" is a broad idea, and is expressed in the French word terroir, particularly useful for expressing the idea of territory in the agri-food economy. This includes, in addition to natural resources, cultural and social aspects (the history and tradition of production) savoir faire, that is, the knowledge and skills that belong to and are shared among human resources in the area [31]. Social relations consist of trust, reciprocity and cooperation between the actors that promote local action [32] and generate endogenous development mechanisms from interaction with place [33]. Institutions are private and public actors that promote actions regulated by formal and informal means.

Figure 2 shows the conceptualization of the Localized Agri-food System (LAFS) which considers a value chain to be embedded in a territory where different stakeholders play a role. These actors can be inside the value chain and directly connected to it (e.g., producers or traders) or outside the value chain (e.g., research and extension, public authorities, etc.) with influencer power over it. Moreover, the value chain can be embedded in the territory, as a local value chain, or simply use the territory as a repository of inputs (mainly work or local resources) for other markets (domestic or international value chains) [34].

How actors interact within the system can influence substantially how LAFSs work, develop and reach results [L1]. This essentially depends on the variety of actors' interests, desires, knowledge, cultures, powers, networks, shared ideas and all the other elements which can influence the vision over the LAFS of each actor operating within it. Thus, Giacomini and Mancini [31] highlight how organization is a key factor in LAFS, requiring governance to establish reciprocal relationships among actors. Torre [35] defines LAFS governance (formal or informal) as the set of regulations, the collaboration between LAFS actors and the legal framework underwritten by institutions. In 
fact, institutions play a key role, since they can favor horizontal (local) development by providing a regulatory framework that legitimizes actions and behaviors [30]. These horizontal relationships constitute the "organization capital" of the LAFS, which grows gradually with the increasing of relationships between companies/actors and institutions [36].

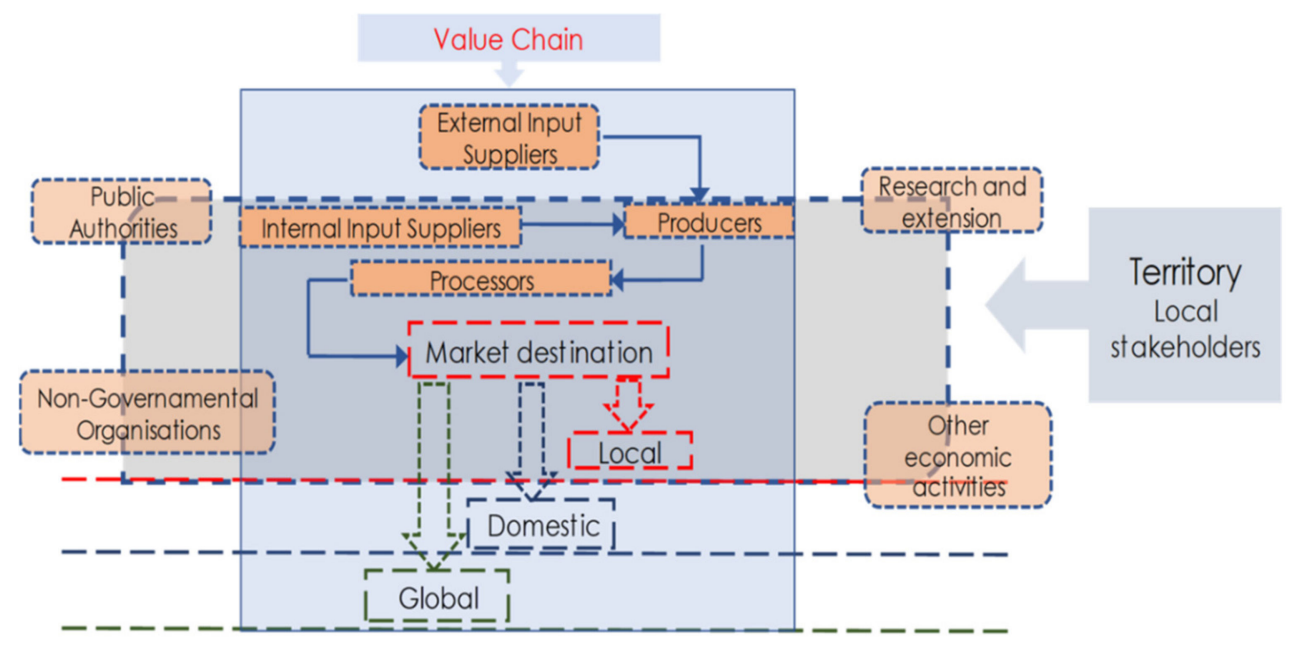

Figure 2. Localized Agri-food System (LAFS) [34].

The governance and the set of different actors, institution and resources (natural or not) have a crucial role in determining LAFS outcome in terms of sustainability in all its dimensions (cultural, social, economic and environmental). Within a LAFS framework, different singular actors who share similar visions, interests and needs can be grouped in clusters of homogeneous actors, in the light of stakeholder theory which in management studies defines a stakeholder as all the individuals/entities who possess an interest (stake) on the operations of a firm [37-40]. The definition can also be extended to wider social processes [41]. All the groups of actors who are linked to a specific social process, being affected and affecting it at the same time by the development of the process itself, either in a positive or in a negative way, can be defined as stakeholders [39,42,43]. Following Starik [44] and Hubacek and Mauerhofer [45] in analyzing a LAFS using an agroecological perspective, the definition of stakeholder can be extended to add the entities present in nature, living or not, in material form or not, which can be harmed by, or benefit from, the performance of a specific social process. An example is an ecosystem, as cultural heritage of future generations.

Multi-stakeholder approaches have now become fundamental for analyzing specific contexts and designing effective interventions for individual local needs. Stakeholder analysis (SA) appeared in the 1980s as a method. It was initially used mainly as a tool for firm managers, but it has become increasingly important over the years for socio-ecological analysis too [41]. SA can be seen as an approach which provides a series of guidelines and methods for understanding a social system through the identification of the key actors involved in its functioning and for the assessment of their respective interests in the system itself $[46,47]$. These methods are extremely adaptable to any context and very useful both for researchers and policy makers in generating and analyzing qualitative data on stakeholders to weigh their interests, importance, influence and resources, in order to assess how they can influence a specific process [47,48]. SA is useful for understanding the position of each stakeholder group and their relations and importance in influencing the success of the process by supporting it or not [49].

SA is appropriate for analyzing a LAFS which is characterized by a high level of complexity and fragmentation of actors on different spatial scales (rural and urban), different temporal visions of objectives and expectations (long vs. short-term), and different institutional and normative scales (local, provincial, regional and national) [50,51]. 
The use of SA can improve the efficiency and effectiveness of the process of analyzing the trade-offs, conflicts and risks linked to each stakeholder in order to design policies or interventions for correcting unexpected negative results and to redistribute costs and benefits among all the stakeholders [46,52]. $\mathrm{SA}$ is also useful for monitoring process and outcome in participatory processes, especially where consensus and participation are fundamental elements of success, in local sustainability projects as in LAFS [47,53-55].

SA methods can be classified by their approach and focus of interest as either descriptive, normative or instrumental $[51,53]$. The descriptive approach is used as a preparatory tool for subsequent studies or organization of a participatory process [56]. The normative approach aims at engaging all representative stakeholders and incorporating them within the process under analysis [53]. Finally, the instrumental approach analyses the behavior of stakeholders so that policy makers can manage the process in order to achieve the desired results [51]. The normative and instrumental approaches are used in this study.

Following Reed et al. [51], SA is used for: (a) identifying all relevant stakeholders; (b) categorizing them into homogenous groups; (c) analyzing their interrelations and connections.

SA is closely based on extensive qualitative methods such as focus group and semi-structured interviews. The processes of analysis are iterative and adaptive to different contexts. For an extensive description of SA methods and applications, see Reed et al. [51] and Schmeer [57]. SA is an interpretative process [58], in which the research activities can be participative and involve stakeholders directly by using a bottom-up approach $[59,60]$. Alternatively, the analysis can be completely top-down, and exclude stakeholders when the analyst has a high level of knowledge on the system studied or when abundant information is available [61,62]. The level of stakeholder participation in the process of analysis depends on the objectives of the study, the resources available and the specific context of study [63].

After the identification phase, the main tool used in sustainability studies for the classification of stakeholders is the interest-influence matrix (I-I matrix), in which stakeholders are positioned in a four quadrant matrix considering their interests and influence over the process studied [46]. The qualitative information is transformed on a scale into quantitative data and inserted into the I-I matrix which shows the dynamics of the process analyzed in graphical form.

Influence is defined as the power or the ability to condition directly or indirectly the development of the process and its outcome [64,65]. Interests are the idea and vision over the process and the stakeholder's trade-offs in a wider conception, which can be utilitarian or not [57]. This highlights the legitimacy of the stakeholder in the process [51].

Following Eden and Ackermann [66], stakeholders are categorized in the I-I matrix according to their ability to intervene in the process as follows: key stakeholders, context setters, subjects and crowd. According to Reed et al. [51], key stakeholders are characterized by having high influence and high interest in the observed process, they are actors who must be actively considered; Those in the context setter category are highly influential, but have little interest—-they should be monitored and followed; Subjects have a high interest, but a low amount of influence-although by definition they are supportive of the process they have no real impact on it; crowd are the stakeholders who have little interest in or influence on the process and cannot be considered in the decision-making processes.

\subsection{Empirical Strategy}

In this study we analyzed the Parma bio-district using an SA in order to study whether the process of creation was beneficial for boosting and spreading agroecological practices within the Parma LAFS, and at a higher level in the regional agri-food system.

\subsubsection{Stakeholder Identification}

We focused on identifying which stakeholders are important for the development of the Parma bio-district as a successful tool for agroecological scaling-up. Identifying stakeholders and the influence-interest attributes was an iterative process. Potential stakeholders were identified mainly 
through: (1) participant observations; (2) semi-structured interviews with the steering group actors; and (3) the recommendations of interviewees, such as snowball sampling or experts' opinion; (4) short interviews with stakeholders identified in Point (3) (Table 1).

Table 1. Research techniques.

\begin{tabular}{ll}
\hline \multicolumn{1}{c}{ TECHNIQUE } & \multicolumn{1}{c}{ DESCRIPTION } \\
\hline Participant/direct observation & $\begin{array}{l}\text { Researchers took part in the steering group and participated in 10 } \\
\text { meetings in the period September 2018-December 2019 to collect } \\
\text { feedback and points of view, and to identify new stakeholder } \\
\text { categories and contacts. }\end{array}$ \\
\hline Semi-structured interviews & $\begin{array}{l}\text { Ten semi-structured interviewed lasting on average one hour were } \\
\text { conducted with the steering group members. }\end{array}$ \\
\hline Snowball sampling/experts' opinion & $\begin{array}{l}\text { Individuals from the steering group were interviewed, identifying } \\
\text { new stakeholder categories and contacts. }\end{array}$ \\
\hline \multirow{3}{*}{ Short interviews } & $\begin{array}{l}\text { Fifteen meetings and short interviews with these stakeholders to } \\
\text { collect feedback and points of view, to analyze their needs related to } \\
\text { the bio-district. }\end{array}$ \\
\hline
\end{tabular}

Initially, a group of researchers of the University of Parma participated in 10 meetings during the period September 2018-December 2019. The University was invited by the steering group to contribute to the construction of the bio-district, mainly thanks to its role as a neutral institution for facilitating dialogue between different actors. In that phase we collected information and coordinated action to identify and involve other stakeholders.

In the second phase, we conducted 10 semi-structured interviews (5 with males and 5 with females) lasting on average $1 \mathrm{~h}$ (Table 2). We selected the interviewees from the steering group, as the most representative key informants over the Parma bio-district. We asked questions on why respondents consider the bio-district useful, their interests and needs connected to bio-district; the main problems and limits in the construction of the bio-district of Parma; the main output expected from the bio-district. At the end of each interview respondents were asked to speak freely about their general opinions on the Parma bio-district and about the stakeholders having the most influence (positive or negative) in order to get a clear view on the vision of each stakeholder group.

Table 2. Actors interviewed.

\begin{tabular}{|c|c|c|c|}
\hline ACTOR & CODE & TYPE & CATEGORY \\
\hline University of Parma & UNIPR & Institution & Research and extension \\
\hline Agriform & AGR & Training center & Research and extension \\
\hline $\begin{array}{l}\text { District of Solidarity } \\
\text { Economy }\end{array}$ & DES & $\begin{array}{l}\text { Association of organic and } \\
\text { SPG producers and consumers }\end{array}$ & $\begin{array}{l}\text { Production and } \\
\text { commercialization }\end{array}$ \\
\hline $\begin{array}{l}\text { Agri-food and Logistics } \\
\text { Center of Parma }\end{array}$ & CAL & Public-private company & $\begin{array}{l}\text { Production and } \\
\text { commercialization }\end{array}$ \\
\hline Rete Bio & $\mathrm{RB}$ & Company & $\begin{array}{l}\text { Production and } \\
\text { commercialization }\end{array}$ \\
\hline Mercatiamo & ME & $\begin{array}{l}\text { Association of organic and } \\
\text { SPG producers and consumers }\end{array}$ & $\begin{array}{l}\text { Production and } \\
\text { commercialization }\end{array}$ \\
\hline Podere Stuard farm & PST & Experimental farm & $\begin{array}{l}\text { Research and extension } \\
\text { Production and } \\
\text { commercialization }\end{array}$ \\
\hline Municipality of Parma & MPR & Institution & Territorial governance \\
\hline Province of Parma & PPR & Institution & Territorial governance \\
\hline Istituto Agrario Bocchialini & $\mathrm{IAB}$ & Secondary School & Research and extension \\
\hline
\end{tabular}


We used snowball sampling and experts' opinion, together with documentations and grey literature to identify the main stakeholders involved directly or indirectly in the bio-district initiative.

Finally, we organized meetings and short interviews with these stakeholders to collect feedback and points of view, and to analyze their needs regarding the bio-district.

\subsubsection{Stakeholder Classification}

After the interviewing process, we listed and classified the stakeholders following the LAFS approach $[30,33]$. We considered the categories they belong to (production, trade, research and extension and territorial governance, which includes unions, producer organizations and associations, and institutions) and the value-chain level (production, processing, distribution).

\subsubsection{Stakeholder Analysis}

After the interviews, we analyzed the stakeholders' position and level of influence and interest in the process using an I-I matrix. We converted on a scale from 0 to 5 the level of influence and interest of each actor on the basis of the interviews, considering two categories: influence and interest. "Influence" is the stakeholder power to help or hinder the process of construction of the bio-district. Elements of stakeholder influence are: (i) leadership, (ii) communication, (iii) resources, (iv) institutional legitimacy, (v) network dimensions. "Interest" expresses the level of stakeholder interest in participating on the bio-district in that they see it as an opportunity to meet their own aims. Elements of "interest" are: (i) Vision of the process, (ii) Coherence with internal aims, (iii) Economic utility, (iv) Visibility and (v) Social development (Table 3). For the evaluation of the final score of interest and influence we considered each subcategory of elements. We used a minimum value of zero if the stakeholder does not have any of the subcategories and a maximum value of five for cases in which the stakeholder holds all subcategories of influence or interest. Our evaluations of the elements were based on the interviews as well as indications and suggestions from experts.

Table 3. Influence and interest elements in the stakeholder analysis (SA).

\begin{tabular}{|c|c|}
\hline \multirow{5}{*}{ INFLUENCE } & $\begin{array}{l}\text { Leadership: ability to manage problems and to influence other stakeholders [64]. It } \\
\text { is one of the sources of power that Galbraith [67] identifies with personality } \\
\text { (individuals). }\end{array}$ \\
\hline & Communication: ability to communicate their characteristics, strategies and ideas. \\
\hline & $\begin{array}{l}\text { Resources: resources that a stakeholder may mobilize to oppose/support the process } \\
\text { [64], investing in communication, networking, etc. It represents the second source of } \\
\text { power that Galbraith [67] identifies with property (material resources). }\end{array}$ \\
\hline & $\begin{array}{l}\text { Institutional Legitimacy: stakeholders' ability or need to organize themselves, } \\
\text { create or join an association or cooperative with an institutional recognition [40]. }\end{array}$ \\
\hline & $\begin{array}{l}\text { Network dimension: ability to create social interaction and networking organization. } \\
\text { It represents the third source of power that Galbraith [67] identifies for an } \\
\text { organization, and he considers it the most important source of power in } \\
\text { modern societies. }\end{array}$ \\
\hline \multirow{5}{*}{ INTEREST } & $\begin{array}{l}\text { Vision on the process: stakeholder adherence to bio-district vision as the realization } \\
\text { of a certain defined future. }\end{array}$ \\
\hline & $\begin{array}{l}\text { Coherence with internal aims: consistency between the mission of the stakeholders } \\
\text { and that of the bio-district (the objectives of the bio-district are coherent with the } \\
\text { internal aims of the stakeholder, expressed in internal agreements or statutes). }\end{array}$ \\
\hline & Economic utility: stakeholder trust in the bio-district capacity to increase business. \\
\hline & $\begin{array}{l}\text { Visibility: stakeholder trust in the bio-district capacity to increase visibility on the } \\
\text { local market. }\end{array}$ \\
\hline & $\begin{array}{l}\text { Social development: stakeholder trust in the bio-district capacity to strengthen the } \\
\text { social economic networks and social inclusion at the territorial level. }\end{array}$ \\
\hline
\end{tabular}




\section{Results}

\subsection{Stakeholder Classification}

Stakeholders were identified and classified following the LAFS approach. We thus identified four categories of stakeholders (production, trade channel, research and extension and territorial governance), and then distributed them according to the level of the value chain level they are most involved in (farming, processing and distribution) (Figure 3).

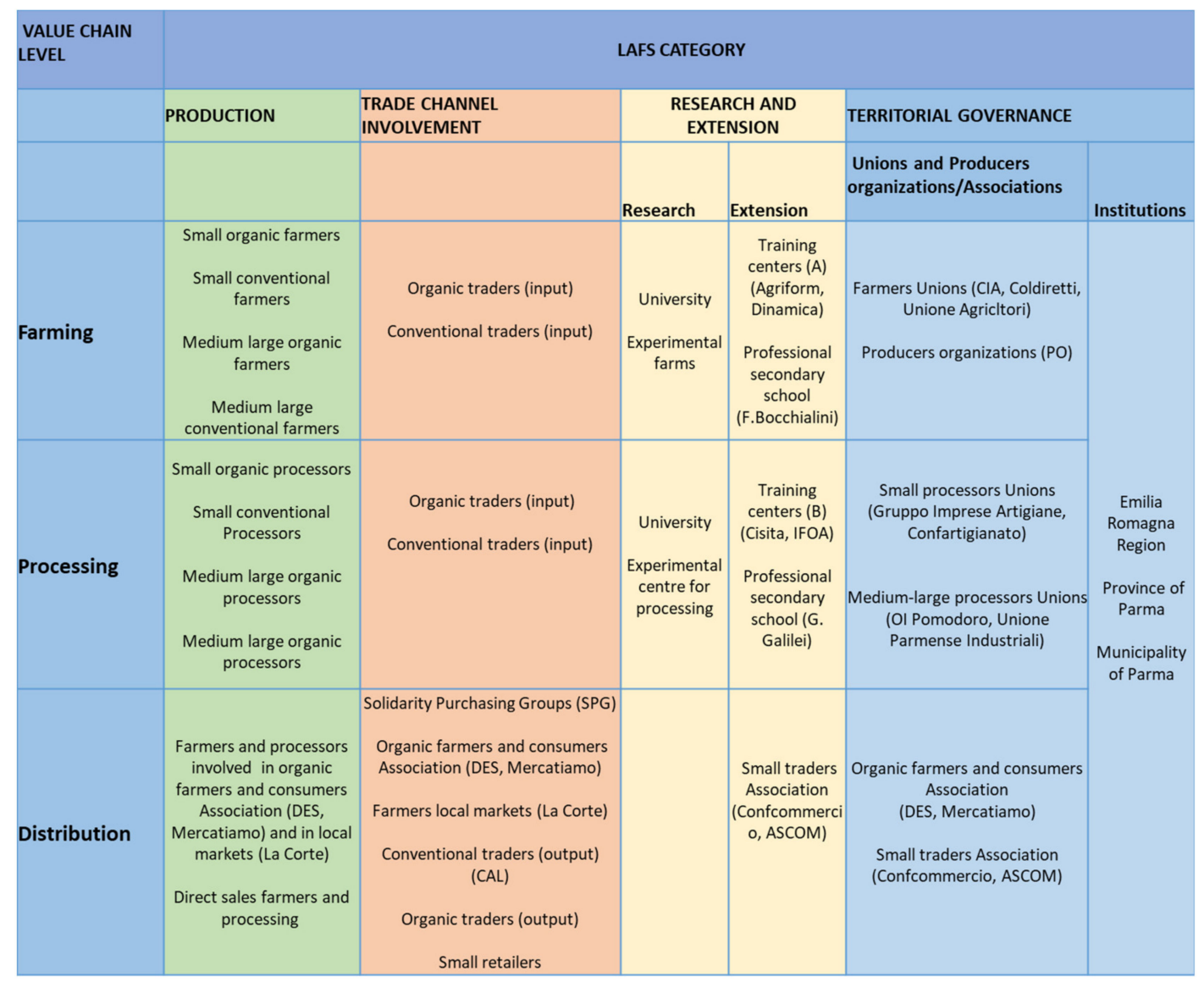

Figure 3. Stakeholder classification.

Stakeholders linked to production are: farmers, processors, organic farming and consumer associations (such as the DES or Mercatiamo) or local farmers markets (such as La Corte, a farmers' market supported by the local administration and formed by organic and conventional small local farmers).

Stakeholders involved in trade channels are: traders of input, Solidarity Purchasing Groups (SPG), organic farmers and consumer associations (such as Mercatiamo and DES), local farmers markets (e.g., La Corte) and small retailers.

The research and extension category is represented by: universities, experimental farms (e.g., Podere Stuard) and training centers (e.g., Agriform and Dinamica, small local training centers running courses mainly on farming and horticulture at the farm level; Cisita and IFOA, local training centers running courses on processing).

Stakeholders making up governance include: farmers' unions (CIA, Coldiretti, Unione Agricoltori), producers' organizations (PO), processors' unions (small: Gruppo Imprese Artigiane, Confartigianato; medium-large: North Italian Tomato Inter Branch Organization, Unione Parmense Industriali); consumer associations and small trader associations. Institutions such as Emilia Romagna region, 
Province of Parma and Municipality of Parma influence the three levels of the value chain. It is interesting to observe the absence of research at the distribution level.

\subsection{Stakeholder Analysis}

The influence-interest matrix identifies, on one hand, the key players with high interest in the project and high influence, and, on the other hand, actors to be involved, with high influence and medium interest (Figure 4). The Key Players (Group A) are mostly institutions (Municipality of Parma, Emilia Romagna region, Province of Parma), small traders' associations and the local university. Stakeholders with high interest in the project, but with medium- low influence power (Group B) are small organic farmers and organic traders.

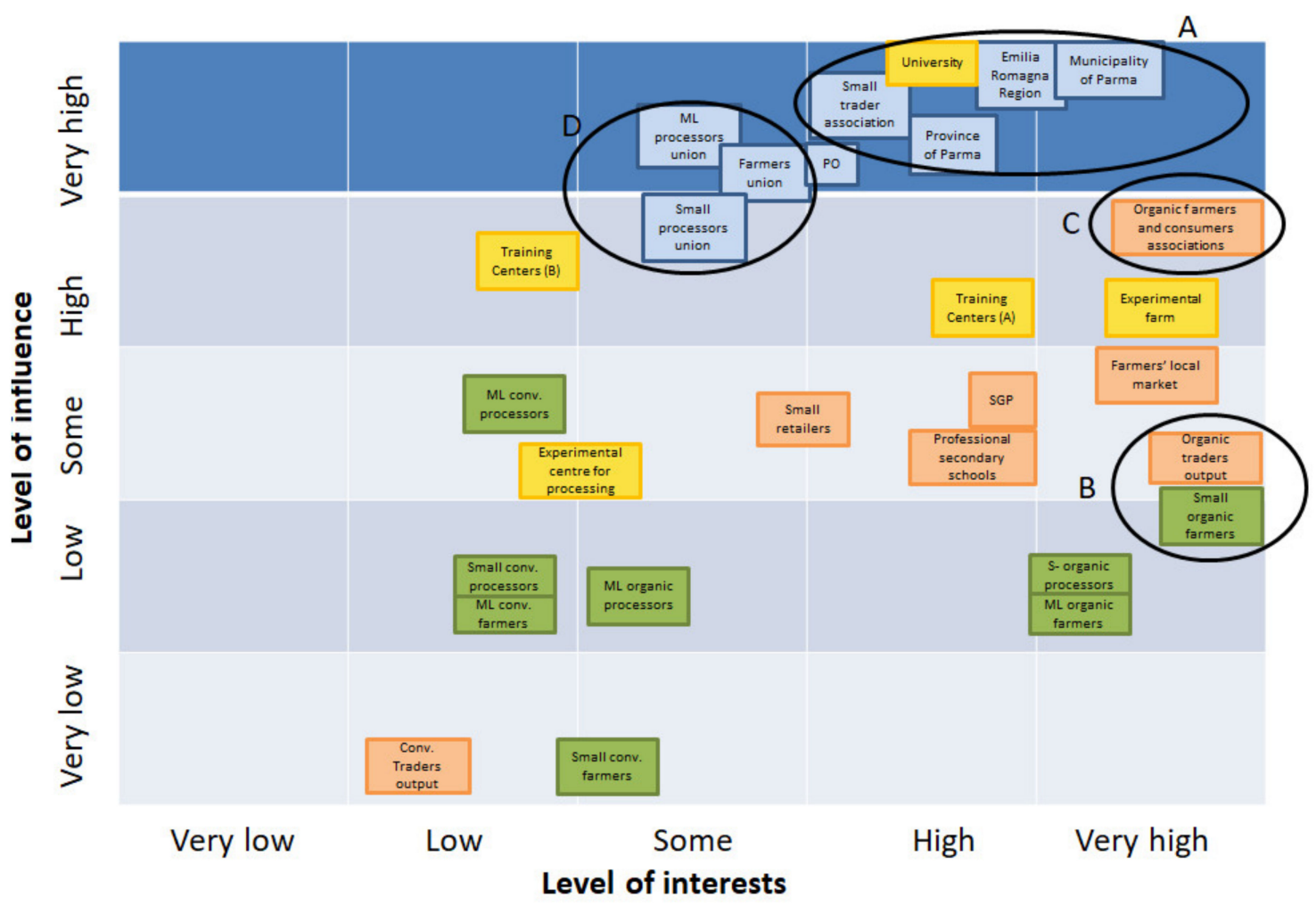

Figure 4. Influence-Interest matrix.

The stakeholders in this category can be defined as important for supporting the process, but they do not have enough power to impact the process without allying with other stakeholders [51]. However, organic farmers and consumer associations, which also represent some small organic farmers, have high interest and a high influence level (Group C). This means that the role of local institutions in facilitating the dialogue with consumers and producers' associations is crucial for the success of the bio-district. Several Italian bio-districts have met difficulties in involving institutions and creating a bottom-up dialogue. This result of the analysis has been used by the founding group of the bio-district to lobby the local government of the Province of Parma and solicit their active participation to the project in promoting awareness among the different municipalities and other local institutions. Furthermore, the Municipality of Parma was commissioned by the founding group to register the promoting committee.

Other important actors to be involved in order to ensure the success of the bio-district are the "intermediate institutions" (Group D) such as processors' unions, farmers' unions and producer organizations (PO) which have a high level of influence and some interest. The Municipality of Parma is currently in charge of contacting and involving these actors, taking advantage of its institutional role. 
Those actors can be defined as context setters as they are highly influential but are not totally involved in the process, and require to be monitored and involved for improving the success of the process [51].

All other stakeholders show a low level of both interest and influence. They can be classified as Crowd as they are not relevant for driving the success or failure of the process. They mainly act in a passive and adaptive way [51]. They should be monitored in view of future alliances and in case of any changes in their interest [40].

\section{Discussion}

The debate on sustainability in the agricultural sector involves consumers, institutions and social movements interested in the environmental health impacts of conventional agriculture and in establishing fair social and economic relationships. Constructing a sustainable rural model thus requires an interdisciplinary approach, and tools for social economic and cultural aspects rather than single production processes. Even in the organic system, the debate on introducing social and territorial aspects is gaining momentum. The organic 3.0 strategy of the International Federation of Organic Agriculture Movements (IFOAM) [68] in fact places organic agriculture in a wider perspective, making an implicit link between the production dimension of organic agriculture and agri-food actors. The objective is to reach "interdependence and real partnerships along the value chain and also on a territorial basis, recognizing the core position of smallholding family farmers, of gender relations and of fairness in trade" [68]. The IFOAM strategy is to anchor the production system to the local economy while promoting the adoption of best practices in terms of ecology, societal needs, economy development, culture and accountability [68]. The direct consequence of the IFOAM strategy is to increase and differentiate the concept of extrinsic quality surrounding organic products guaranteed by the organic label. EU regulations of organic production do not, however, consider local dimensions and peculiarities in terms of production and consumption systems. This is a weak point in organic value chains, and a new framework is in fact needed to connect the production system to social, economic and cultural sustainability.

Agroecology offers an inclusive approach that includes socioeconomic, cultural and sociopolitical dimensions as well as an ecological-agronomical dimension. The socioeconomic and cultural dimension consists of revitalizing local resources and building organizational structures between local farmers and other economic sectors. The sociopolitical dimension makes agroecology a political tool which can have an impact on decision making in the agri-food system [69,70]. Agroecology, in fact, is the endogenous concept of rural development in which the heterogeneity of rural contexts is recreated from cultural and ecological local resources through collective forms of social action [71]. It could thus be assumed that agroecology could in fact be created on the basis of organic agriculture, in local food production systems, and effectively promote the development of sustainable rural development models.

The case of the Parma bio-district offers some interesting points of analysis. It reflects the three dimensions of agroecology: (i) it promotes the adoption of agroecological practices under stricter regulation than the EU Regulation framework, coherently with the productive dimension; (ii) it creates a local network between stakeholders, from farm to fork, in order to improve economic and social sustainability; (iii) it interacts with local administrations with the aim of influencing food policy at the local level (e.g., promoting the introduction of bio-district products in schools canteens, increasing farmers' markets).

Unlike other bio-districts, the Parma bio-district is characterized by a high heterogeneity of stakeholders who range from small operators to large farmers, organic farmers, consumer associations and processors' unions. It also has agreements with educational and training institutions, experimental farms and research institutions, and thus takes part in education and research initiatives with the aim of making the rural system more sustainable.

This "biodiversity of stakeholders" is one of the main aspects of the bio-district, and was taken into consideration from the early stages in an attempt to reduce information asymmetry between stakeholders and to increase the trust and the convergence of interests. 
Rather than insisting on a rigid separation between "organic" and "agroecology" systems, the Parma bio-district embodies an innovative and comprehensive approach aimed to provide economic, social and environmental benefits to a wider range of stakeholders. Its strategy is based on the coexistence of different production and consumption models, as a solution to reduce the rigidity of some aspects of the system. The final goal is to facilitate the engagement of a wider range of stakeholders, respecting their characteristics and enhancing their value. This is coherent with the LAFS approach which considers bio-districts embedded in a territory where different stakeholders set their own strategy and interact with each other.

On the basis of this comprehensive approach, the bio-district facilitates a synergetic relation between organic and agroecological agriculture, spreading organic agriculture in a territorial dimension, and facilitating its scaling-up towards agroecology.

The coexistence of different stakeholders and "cross fertilization" is an important opportunity for scaling up and shifting to a more agroecological approach. Spreading the concepts and characteristics of agroecology would bring several benefits to producers and consumers. Different models of production, processing and consumption could coexist within a more inclusive framework if they are based on shared principles and technical schemes for recognition and control. Such quality and certification schemes and labels should be formally accountable and flexible enough to be affordable for all the stakeholders involved. The adoption of increasing levels of quality standards, which correspond to an increasing level of a guarantee system, could facilitate the dialectical dynamic between the conventionalization and the novel practices where structural mismatches [72] would move forward novel and more sustainable practices within dynamic systems of the bio-district.

At the same time, this coexistence and convergence of different models toward a flexible approach could, however, present risks in terms of trade-offs among stakeholders having different levels of interest and influence.

Considering that the actors with the greatest influence and interest are local institutions, there is a risk of excessive bureaucratization or conventionalization which could impact negatively on the implementation and approach of the bio-district. On the other hand, the involvement of local institutions is a possible key to success, especially considering that other bio-districts have experienced difficulties in setting up and managing bottom-up dialogue.

There may be other risks in the relations between small traders' associations (with high influencing power) and associations representing consumers, producers and farmers' market actors (which show high interest but less influencing power. The aims of these two groups may be in conflict. Small traders are in fact interested in revitalizing the network of small local shops, whereas the second group consider direct sales and the direct relationship between producers and consumers as the most appropriate type of distribution as it can build up relationships of mutual knowledge and trust.

As small organic farmers and traders have a high level of interest but a low level of influential power, it is interesting to note that their requirements could in fact be put forward by organic farmers and consumers' associations which have more opportunities to negotiate with local administrations. The high level of interest on the part of the organic farmers and consumer associations could in fact be used in favor of a "market segmentation strategy", particularly by following PGS requirements. These, in fact, are leading the whole system in continuous incremental improvements towards adopting best practices. Organic farmers and consumer associations could also be helpful in improving organic certification schemes which fulfill legal requirements by substituting certain inputs without redesigning operations as a whole $[6,73]$.

So, scaling up towards an agroecological model is possible where the social fabric includes associations which follow agroecological principles and which can negotiate with local administrations or other stakeholders. It is important to highlight that these associations have a significant participation of women even if the institutional representatives, with a higher influence and decision power, are mainly men. 
Because stakeholders are many and varied, governance is an important element for the scaling-up towards agroecology. The co-existence of stakeholders is related to the will or ability to define common principles coherent with the agroecological approach. The framework needs to be flexible, with clear and transparent rules, but it also needs to have a very clear vision towards sustainability and social responsibility considered from an agroecological point of view. The governance of the whole process is probably the key element to ensure that all stakeholders embrace agroecology as a practice and that there can be cross-fertilization in activities and dialogue.

The Agroecology Europe Forum [74] defines the principles that should inspire the new model of European organic agriculture. It identifies the following points: (i) Definition and concepts; (ii) Education; (iii) Training, and knowledge sharing; (iv) Research approach and funding; (v) Productivity and practices; (vi) Food policies systems and consumer awareness; (vii) Co-optation. All of these aspects are well-represented in the Parma bio-district.

Currently, organic agriculture is more widely known than agroecology in the Province of Parma. The bio-district could, however, raise the level of awareness and knowledge of agroecology as a practice, a science, and a socio-political movement. As an alliance between the University, secondary schools, training centers and experimental farms, the bio-district is in a strong position to improve education, research and training in agroecology and sustainable agriculture.

At the research and practical level, there is clearly a high level of interest in and influence of the Emilia Romagna region, the Province and the Municipality of Parma, and a relatively high level of interest and influence among training centers, experimental farms and technical schools. There is also a high level of interest from the small and medium farmers and processors, which is of great practical use in creating a fertile environment for interaction and cross-fertilization. Public institutions could support and finance the process, regulating and communicating interdisciplinary agroecology research and field practice, linking universities, training centers, schools and experimental farms with smallholders and medium-sized farmers.

Mutual cooperation between stakeholders of the Parma bio-district might boost the development of a holistic and integrated sustainable local agri-food system embracing research, methods and practices between different stakeholders in schools, universities and other educational institutions, and local farms, and design a constellation of interconnected practices.

The Parma bio-district is an interesting case study for analysis of whether and how an organic scheme at the local level can follow an agroecological approach and whether it can be a tool for scaling up agroecology. This study shows that stakeholders involved in the Parma bio-district potentially have the opportunity to make a structural change towards agroecology in the area. But the outcome of the process is uncertain and depends closely on the governance of the process.

\section{Conclusions}

The debate about a sustainable agri-food system is closely linked to the local dimension, where socioeconomic and political aspects interact with the production system. Agroecology is a multidisciplinary approach which offers a framework to re-design a sustainable agri-food system "from farm to fork". It can make an important contribution to the design of sustainable agro-eco systems at the farm level and to the construction of sustainable food networks. The cultural dimension, and networking among farmers, citizens and institutions become political tools impacting on decision making. In the European context, the debate on bio-districts is based on the idea that they can be a tool to integrate agri-food systems and local areas in order to improve quality of life in rural communities, starting from a model of organic production and consumption. The aim of this paper is to verify whether bio-districts can also be a tool for scaling-up towards agroecology, and it has used a case study of the Parma bio-district. The LAFS approach was used in the analysis because of its usefulness in investigating the local dimension. LAFS considers the link between agri-food production and the area, and the interaction among local stakeholders to promote collective action in local development strategies. Identifying the path of the bio-district in agroecology requires a survey analysis of LAFS 
stakeholders. Bio-district stakeholders were thus classified and positioned in an I-I matrix that shows their level of interest in the Parma bio-district initiative, and their ability to influence the process.

General considerations and conclusions can be drawn from the Parma bio-district analysis. Bio-districts can be a tool for a scaling up towards agroecology because they facilitate a synergetic relation between organic and agroecological agriculture, spreading organic agriculture across an area and facilitating its scaling-up towards agroecology. But the coexistence of different stakeholders could present risks in terms of trade-offs among those having different levels of interest and influence, and may bring a risk that the whole process becomes excessively bureaucratized. A process of scaling up is in fact more likely in an area where agroecology is represented and supported by local associations taking part in negotiations with public institutions. The involvement of research and educational institutions, experimental farms, and training centers in promoting dialogue with public administration bodies and farmers' unions is important as they are politically neutral with regard to the other stakeholders.

Parma Province is characterized by an important gastronomic culture and an increasing interest in quality schemes by consumers. However, the presence and interaction among universities, research centers, the productive sector, the commercial network and institution is common in others Italian and European contexts. Thus, the Parma case study shows how the involvement of a wide variety of stakeholders can be a way to overcome small alternative experiences. However, governance becomes an important element in scaling up towards agroecology. Governance is required to lower the degree of asymmetry of information and to facilitate the definition of common principles and draw a clear path towards sustainability within an agroecological framework. The governance of the entire process might be the key to enable dialogue among stakeholders for facilitating "cross-fertilization" and, on the other hand, ensuring that the process does not become conventionalized and formulaic.

Once the stakeholder platform has been created, it is important that the research could support the bio-district by defining and drafting production regulations. Although the EU organic regulations represent the basic standard to participate to the bio-district, further elements linked to environmental and social sustainability are expected to be introduced for scaling up towards agroecology. However, it would be important that the specifications can be accepted on both the consumption and production sides. On the one hand, the rules have to be socially accepted by consumers; on the other hand, they can be suitable and accepted by producers, without causing excessive costs that could become an entry barrier.

Author Contributions: M.G.: conceptualization. data curation, formal analysis, methodology, writing original draft, writing review and editing; M.M.: conceptualization, investigation, writing-original draft; J.P.S.: conceptualization, investigation, writing original draft, writing review and editing; F.A.: conceptualization, investigation, supervision, methodology, writing original draft, writing review and editing; A.P.: conceptualization, methodology, supervision, writing original draft, writing review and editing. All authors have read and agreed to the published version of the manuscript.

Funding: This research received no external funding.

Acknowledgments: The authors thank the Board of the Solidarity Economic District of Parma and the Board of Mercatiamo for the support given to the discussion of the paper. Nevertheless, the authors are fully responsible for the content.

Conflicts of Interest: The authors declare no conflict of interest.

\section{References}

1. Food and Agriculture Organization of the United Nations (FAO). Transforming Food and Agriculture to Achieve the SDGs: 20 Interconnected Actions to Guide Decision-Makers; Food and Agriculture Organization: Rome, Italy, 2018.

2. EU Council. On organic production and labelling of organic products and repealing Council Regulation (EEC) No 2092/91. In Official Journal of the European Union; European Union: Brussels, Belgium, 2007; Volume 189, pp. 20-27.

3. Altieri, M.A. Agroecology: The Science of Sustainable Agriculture; Westview Press: Boulder, CO, USA, 1995. 
4. Wezel, A.; Bellon, S. Mapping Agroecology in Europe. New Developments and Applications. Sustainability 2018, 10, 2751. [CrossRef]

5. Calame, M.; Darrot, C. Comprendre L'agroécologie: Origines, Principes, et Politiques; Editions Charles Léopold Mayer: Paris, France, 2016.

6. Herren, H.R.; Hilbeck, A.; Hoffmann, U.; Home, R.; Levidow, L.; Müller, A.; Nelson, E.; Oehen, B.; Pimbert, M. Feeding the people: Agroecology for nourishing the world and transforming the agri-food system. IFOAM EU Group 2015, unpublished work.

7. Wezel, A.; Goris, M.; Bruil, J.; Félix, F.G.; Peeters, A.; Bàrberi, P.; Bellon, S.; Migliorini, P. Challenges and Action Points to Amplify Agroecology in Europe. Sustainability 2018, 10, 1598. [CrossRef]

8. Rete Rurale Nazionale. BIOREPORT 2016 L'agricoltura Biologica in Italia; Rete Rurale Nazionale: Rome, Italy, 2017.

9. Altieri, M.A.; Nicholls, C. Un método agroecológico rápido para la evaluación de la sostenibilidad de cafetales. Manejo Integr. Plagas 2002, 64, 17-24.

10. Agroecology EU. Available online: https://www.agroecology-europe.org/ (accessed on 15 March 2020).

11. Jablonski, B.; Thilmany McFadden, D. What is a 'Multiplier' Anyway? Assessing the Economics of Local Foods Systems Toolkit. J. Agric. Food Syst. Community Dev. 2019, 8, 1-8. [CrossRef]

12. Urban Food Futures. Available online: https://urbanfoodfutures.com/ (accessed on 15 March 2020).

13. EU Council. On organic production of agricultural products and indications referring thereto on agricultural products and foodstuffs. In Official Journal of the European Union; European Union: Brussels, Belgium, 1991.

14. EU Council. Relativo alla produzione biologica e all'etichettatura dei prodotti biologici e che abroga il regolamento (CEE) n. 2092/91. In Official Journal of the European Union; European Union: Brussels, Belgium, 2007; Volume 28.

15. Arbenz, M. Organic and agroecology: Synergetic approaches. Farm. Matters 2018, 3, 21.

16. Bellon, S. Contributions croisées de l'agriculture biologique à la transition agroécologique. Innov. Agron. 2016, 51, 121-138.

17. Migliorini, P.; Wezel, A. Converging and diverging principles and practices of organic agriculture regulations and agroecology. A review. Agron. Sustain. Dev. 2017, 37, 63. [CrossRef]

18. Niggli, U. Incorporating Agroecology into Organic Research-An Ongoing Challenge. Sustain. Agric. Res. 2015, 4, 149. [CrossRef]

19. IFOAM. One Earth, Many Hands; Annual Report, International Federation of Organic Agriculture Movements: Bonn, Germany, 2008.

20. Hartmann, M.; Yeh, C.H.; Amilien, V.; Čeliković, Z.; Csillag, P.; Filipović, J.; Giraud, G.; Gorton, M.; Kuč, V.; Menozzi, D.; et al. Deliverable 8.1: Report on Quantitative Research Findings on European Consumers' Perception and Valuation of EU Food Quality Schemes As Well As Their Confidence in Such Measures; Strength2food Project: Bonn, Germany, 2019.

21. Mattas, K.; Tsakiridou, E.; Karelakis, C.; Chousou, C.; Lazaridou, D.; Amilien, V.; Arfini, F.; Bellassen, V.; Brecic, R.; Dries, L.; et al. Deliverable 10.1: Report on Quantitative Research Findings on European Consumers' Perception and Valuation of EU Food Quality Schemes As Well As Their Confidence in Such Measures; Synthesis of findings (WPs 3 to 8), Strength2food Project: Thessaloniki, Greece, 2019.

22. Becattini, G. The Marshallian industrial district as a socio-economic notion. Revue Déconomie Industrielle 2017, 157, 13-32. [CrossRef]

23. Belletti, G.; Marescotti, A.; Touzard, J.-M. Geographical Indications, Public Goods, and Sustainable Development: The Roles of Actors' Strategies and Public Policies. World Dev. 2017, 98, 45-57. [CrossRef]

24. AIAB. I Bio-Distretti in Italia e in Europa: Un Nuovo Modello Culturale. Bio Agric. 2014, 5/8, $145-146$.

25. Pugliese, P.; Zanasi, C.; Basile, S. L'agricoltura in Chiave Territoriale L'esperienza dei Bio-Distretti; SINAB: Rome, Italy, 2015.

26. CREA. I distretti biologici in Italia. Agriregionieuropa 2020. in pubblicazione.

27. Gazzetta Ufficiale della Repubblica Italiana. Supplemento Ordinario Alla; Gazzetta Ufficiale: Rome, Italy, 2017; Volume 302.

28. Triantafyllidis, A.; Pietromarchi, A.; Pietromarchi, A.C.; Colombo, L. Veicolazione delle Esperienze di Biodistretti Italiani. I Modelli di Governance e le Buone Pratiche dei Biodistretti; FIRAB: Rome, Italy, 2017. 
29. Cozzi, E.; Donati, M.; Mancini, M.C.; Guareschi, M.; Veneziani, M. PDO Parmigiano Reggiano Cheese in Italy. In Sustainability of European Food Quality Schemes: Multi-Performance, Structure, and Governance of PDO, PGI, and Organic Agri-Food Systems; Arfini, F., Bellassen, V., Eds.; Springer International Publishing: Cham, Switzerland, 2019; pp. 427-449.

30. Muchnik, J. Sistemas agroalimentarios localizados: Evolución del concepto y diversidad de situaciones. In Proceedings of the III Congreso Internacional de la Red SIAL "Sistemas Agroalimentarios Locales" Alimentación y Territorios “ALTER 2006”, Baeza, Spain, 18-21 October 2006.

31. Giacomini, C.; Mancini, M.C. Organisation as a key factor in Localised Agri-Food Systems (LAFS). Bio-Based Appl. Econ. 2015, 4. [CrossRef]

32. Zambrano, J.P. Sistemi agroalimentari localizzati: Dall'agroindustria all'agglomerazione produttiva. Sviluppo Locale 2010, 14, 21-43.

33. Boucher, F. L'agro-industrie rurale et les systèmes agroalimentaires localisés: De nouvelles approches pour le développement territorial. In Proceedings of the XLIIIe Colloque de l'Asrdlf Les Dynamiques Territoriales: Débats et Enjeux des Différentes Approches Disciplinaires, Grenoble, France, 11-13 July 2007.

34. Arfini, F.; Antonioli, F.; Donati, M.; Gorton, M.; Mancini, M.C.; Tocco, B.; Veneziani, M. Conceptual Framework. In Sustainability of European Food Quality Schemes: Multi-Performance, Structure, and Governance of PDO, PGI, and Organic Agri-Food Systems; Arfini, F., Bellassen, V., Eds.; Springer International Publishing: Cham, Switzerland, 2019; pp. 3-21.

35. Torre, A. Economie de la proximité et activités agricoles et agro-alimentaires. Eléments d'un programme de recherche. Revue dEconomie Régionale Urbaine 2000, 3, 407-426.

36. Aubert, F.; Guérin, M.; Perrier-Cornet, P. Organisation et territoire: Un cadre d'analyse appliqué aux espaces ruraux. Revue dEconomie Régionale Urbaine 2001, 3, 393-413. [CrossRef]

37. Freeman, R.E. Strategic Management: A Stakeholder Approach; Pitman Publishing Ltd.: Boston, MA, USA, 1984.

38. Freeman, R.E.; Reed, D.L. Stockholders and Stakeholders: A New Perspective on Corporate Governance. Calif. Manag. Rev. 1983, 25, 88-106. [CrossRef]

39. Phillips, R.; Freeman, R.E.; Wicks, A.C. What Stakeholder Theory Is Not. Bus. Ethics Q. 2003, 13, 479-502. [CrossRef]

40. Mitchell, R.K.; Agle, B.R.; Wood, D.J. Toward a Theory of Stakeholder Identification and Salience: Defining the Principle of Who and What Really Counts. Acad. Manag. Rev. 1997, 22, 853-886. [CrossRef]

41. Pronti, A.; Nobile, G.; Pagliarino, E. La Stakeholder Analysis per la gestione dei beni comuni e delle risorse naturali: Metodologie e letteratura. Quad. IRCrES-CNR 2018, 3, 3-28.

42. Harrison, J.S.; Freeman, R.E. Stakeholders, Social Responsibility, and Performance: Empirical Evidence and Theoretical Perspectives. Acad. Manag. J. 1999, 42, 479-485. [CrossRef]

43. Bowie, S.N. The moral obligations of multinational corporations. In Problems of International Justice; Luper-Foy, S., Ed.; Routledge: Boulder, CO, USA, 1988; pp. 97-113.

44. Starik, M. Should Trees Have Managerial Standing? Toward Stakeholder Status for Non-Human Nature. J. Bus. Ethics 1995, 14, 207-217. [CrossRef]

45. Hubacek, K.; Mauerhofer, V. Future generations: Economic, legal and institutional aspects. Futures 2008, 40, 413-423. [CrossRef]

46. Grimble, R.; Wellard, K. Stakeholder methodologies in natural resource management: A review of principles, contexts, experiences and opportunities. Socio-Econ. Methods Renew. Nat. Resour. Res. 1997, 55, 173-193. [CrossRef]

47. Le, N.; Nguyen, T.; Zhu, D. Understanding the Stakeholders' Involvement in Utilizing Municipal Solid Waste in Agriculture through Composting: A Case Study of Hanoi, Vietnam. Sustainability 2018, 10, 2314. [CrossRef]

48. Varvasovszky, Z.; Brugha, R. A stakeholder analysis. Health Policy Plan. 2000, 15, 338-345. [CrossRef]

49. Brugha, R.; Varvasovszky, Z. Stakeholder analysis: A review. Health Policy Plan. 2000, 15, 239-246. [CrossRef]

50. Prell, C.; Hubacek, K.; Reed, M.; Quinn, C.; Jin, N.; Holden, J.; Burt, T.; Kirby, M.; Sendzimir, J. If you have a hammer everything looks like a nail: Traditional versus participatory model building. Interdiscip Sci. Rev. 2007, 32, 263-282. [CrossRef]

51. Reed, M.S.; Graves, A.; Dandy, N.; Posthumus, H.; Hubacek, K.; Morris, J.; Prell, C.; Quinn, C.H.; Stringer, L.C. Who's in and why? A typology of stakeholder analysis methods for natural resource management. J. Environ. Manag. 2009, 90, 1933-1949. [CrossRef] 
52. Grimble, R.; Chan, M.-K. Stakeholder analysis for natural resource management in developing countries. Nat. Resour. Forum 1995, 19, 113-124. [CrossRef]

53. White, D.; Jones, J.; Maciejewski, R.; Aggarwal, R.; Mascaro, G. Stakeholder Analysis for the Food-Energy-Water Nexus in Phoenix, Arizona: Implications for Nexus Governance. Sustainability 2017, 9 , 2204. [CrossRef]

54. Lam, J.; Yap, W. A Stakeholder Perspective of Port City Sustainable Development. Sustainability 2019, $11,447$. [CrossRef]

55. Lange, A.; Siebert, R.; Barkmann, T. Sustainability in Land Management: An Analysis of Stakeholder Perceptions in Rural Northern Germany. Sustainability 2015, 7, 683-704. [CrossRef]

56. Donaldson, T.; Preston, L.E. The Stakeholder Theory of the Corporation: Concepts, Evidence, and Implications. Acad. Manag. Rev. 1995, 20, 65-91. [CrossRef]

57. Schmeer, K. Stakeholder Analysis Guidelines, Policy Toolkit for Strengthening Health Sector Reform; World Health Organization: Geneva, Switzerland, 2000.

58. Aaltonen, K. Project stakeholder analysis as an environmental interpretation process. Int. J. Proj. Manag. 2011, 29, 165-183. [CrossRef]

59. Jepsen, A.L.; Eskerod, P. Stakeholder analysis in projects: Challenges in using current guidelines in the real world. Int. J. Proj. Manag. 2009, 27, 335-343. [CrossRef]

60. Pomeroy, R.; Douvere, F. The engagement of stakeholders in the marine spatial planning process. Mar. Policy 2008, 32, 816-822. [CrossRef]

61. Rowe, G.; Frewer, L.J. Public Participation Methods: A Framework for Evaluation. Sci. Technol. Hum. Values 2000, 25, 3-29. [CrossRef]

62. Reed, M.S. Stakeholder participation for environmental management: A literature review. Biol. Conserv. 2008, 141, 2417-2431. [CrossRef]

63. Luyet, V.; Schlaepfer, R.; Parlange, M.B.; Buttler, A. A framework to implement Stakeholder participation in environmental projects. J. Environ. Manag. 2012, 111, 213-219. [CrossRef] [PubMed]

64. Rastogi, A.; Badola, R.; Hussain, S.A.; Hickey, G.M. Assessing the utility of stakeholder analysis to Protected Areas management: The case of Corbett National Park, India. Conserv. Manag. Hum. Domin. Landsc. Case Stud. India 2010, 143, 2956-2964. [CrossRef]

65. Romanelli, A.; Massone, H.E.; Escalante, A.H. Stakeholder Analysis and Social-Biophysical Interdependencies for Common Pool Resource Management: La Brava Wetland (Argentina) as a Case Study. Environ. Manag. 2011, 48, 462-474. [CrossRef] [PubMed]

66. Eden, C.; Ackermann, F. Making Strategy: The Journey of Strategic Management; SAGE: London, UK, 1998.

67. Galbraith, J.K. The Anatomy of Power; Houghton Mifflin: Boston, MA, USA, 1983.

68. Ifoam Organic 3.0-The Next Phase of Organic Development. Available online: https://www.ifoam.bio/en/ innovation-organic-30/organic-30-next-phase-organic-development (accessed on 15 March 2020).

69. Ottmann, G.; Sevilla Guzmán, E. Las dimensiones de la Agroecología. In Manual de Olivicultura Ecológica. Instituto de Sociología y Agricultura Ecológica; VV.AA.: Utrecht, The Netherlands, 2004.

70. Guzmán, G.I.; López-García, D.; Román, L.; Alonso, A.M. Participatory action research for an agroecological transition in Spain. In Agroecology: A Transdisciplinary, Participatory and Action-Oriented Approach; Méndez, V.E., Bacon, C.M., Cohen, R., Eds.; CRC Press: Boca Raton, FL, USA, 2016; pp. 140-160.

71. Sevilla Guzmán, E.; Soler Montiel, M. Del desarrollo rural a la agroecología. Hacia un cambio de paradigma. Documentación Social 2009, 155, 23-39.

72. Van der Ploeg, J.D. The political economy of agroecology. J. Peasant Stud. 2020, 1-24. [CrossRef]

73. Darnhofer, I.; Lindenthal, T.; Bartel-Kratochvil, R.; Zollitsch, W. Conventionalisation of organic farming practices: From structural criteria towards an assessment based on organic principles. A review. Agron. Sustain. Dev. 2010, 30, 67-81. [CrossRef]

74. Agroecology EU Forum 2017. Available online: https://www.agroecology-europe.org/agroecology-forum2017/ (accessed on 17 March 2020).

(C) 2020 by the authors. Licensee MDPI, Basel, Switzerland. This article is an open access article distributed under the terms and conditions of the Creative Commons Attribution (CC BY) license (http://creativecommons.org/licenses/by/4.0/). 